\title{
SISTEM PENDUKUNG KEPUTUSAN PENILAIAN CALON SUPERVISOR DENGAN MENGGUNAKAN METODE FUZZY ANALYTICAL HIERARCHY PROCESS (FAHP)
}

\author{
Fauziani Tanzil ${ }^{1)}$, Sudin Saepudin ${ }^{2)}$, Sihabudin ${ }^{3)}$ Nunik Destria Arianti ${ }^{4)}$ dan Adithia Erfina ${ }^{5)}$ \\ 1, 2,3, 4, 5),Program Studi Sistem Informasi, Universitas Nusa PutraSukabumi Jl. Raya Cibolang No. 21 \\ Sukabumi, Jawa Barat, 43152 Indonesia, Tlp. 0266210594 \\ * Korespondensi: e-mail: e-mail: fauziani1605@gmail.com ${ }^{1)}$, \\ sudin.saepudin@nusaputra.ac.id ${ }^{2)}$,sihabudin@nusaputra.ac.id ${ }^{3)}$ nunik.destria@nusaputra.ac.id ${ }^{4)}$, \\ adithia.erfina@ nusaputra.ac.id ${ }^{5)}$
}

\begin{abstract}
ABSTRAK
Penilaian kinerja adalah kegiatan yang dilakukan dalam sebuah perusahaan untuk mengevaluasi pelaksanaan kerja karyawan secara teratur. Selain itu penilaian kinerja dapat dibuat untuk memberikan informasi tentang pengangkatan jabatan ataupun penentuan gaji suatu karyawan. Penelitian ini dilakukan di PT. PT.Mitra Telindo Nusantara untuk pengangkatan calon supervisor agar Sumber Daya Manusia (SDM) yang terdapat diperusahaan dapat dioptimalkan sesuai dengan yang di harapkan perusahaan. Pengangkatan calon supervisor ini diberikan kepada setiap kepala toko cabang. Kepala toko cabang yang terpilih akan menempati jabatan supervisor area. Terdapat masalah dalam penilaian karyawan di PT.Mitra Telindo Nusantara yang masih dilakukan secara manual membuat proses penilaian membutuhkan waktu yang lama dan tidak akurat, dikarenakan proses penilaian yang bersifat subyektif sehingga diperlukan analisis pendukung keputusan untuk menentukan calon supervisor. Salah satu metode yang digunakan untuk mendukung keputusan adalah metode Fuzzy Analytical Hierarchy Process (FAHP). F-AHP merupakan suatu metode analisis yang dikembang dari AHP dengan pendekatan konsep Triangular Fuzzy Number (TFN). F-AHP dianggap lebih baik dalam mendeskripsikan keputusan yang samar-samar dari pada AHP. Hasil dari perhitungan metode Fuzzy AHP dapat disimpulkan bahwa terdapat 4(empat) rekomendasi calon spv yang terbaik yaitu Cut Nurbaeti dengan bobot 0.997, Rahmi dengan bobot 0.976, Deni 0.940, dan Arbagin Bakri 0.936.
\end{abstract}

Kata Kunci: Penilaian Kinerja, Supervisor, PT.Mitra Telindo Nusantara, Fuzzy AHP

\begin{abstract}
Performance appraisal is an activity carried out in a company to evaluate the work of employees on a regular basis. In addition, a performance appraisal can be made to provide information about the appointment or determination of an employee's salary. This research was conducted at PT. Mitra Telindo Nusantara for the appointment of prospective supervisors so that the Human Resources (HR) in the company can be optimized as expected by the company. The appointment of prospective supervisors is given to each branch store head. The head of the selected branch store will occupy the position of the area supervisor. There is a problem in the assessment of employees at PT. Mitra Telindo Nusantara which is still done manually making the assessment process take a long time and is inaccurate, due to the subjective assessment process so decision support analysis is needed to determine prospective supervisors. One of the methods used to support decisions is the Fuzzy Analytical Hierarchy Process (FAHP) method. F-AHP is an analytical method developed from AHP with a Triangular Fuzzy Number (TFN) concept approach. $F-A H P$ is considered better at describing vague decisions than AHP. The results of the calculation of the Fuzzy AHP method can be concluded that there are 4 (four) recommendations for the best SPV candidates, namely Cut Nurbaeti with a weight of 0.997, Rahmi with a weight of 0.976, Deni 0.940, and Arbagin Bakri 0.936.
\end{abstract}

Keywords: Performance Assessment, Supervisor, PT. Mitra Telindo Nusantara, Fuzzy AHP 


\section{Pendahuluan}

Penilaian kinerjaadalah kegiatan yang dilakukan dalam sebuah perusahaan untuk mengevaluasi pelaksanaan kerja karyawan secara teratur. Penilaian kinerja adalah kegiatan yang dilakukan dalam sebuah perusahaan untuk mengevaluasi pelaksanaan kerja karyawan secara teratur. Selain itu penilaian kinerja dapat dibuat untuk memberikan informasi tentang pengangkatan jabatan ataupun penentuan gaji suatu karyawan.[1]

PT.Mitra Telindo Nusantara merupakan usaha perseorangan dengan pengkhususan diri dibidang penjualan telepon genggam dan memiliki 41 toko cabang di kawasan jabodetabek. Agar memiliki keunggulan bersaing, dan dapat bertahan hidup serta dapat meningkatkan efesiensi dan produktivitas perusahaan melalui sumber daya manusia (SDM), pengelolaan Sumber Daya Manusia (SDM) merupakan suatu penentu keberhasilan kinerja dari perusahaan tersebut.

Dalam meningkatkan kualitas karyawan, PT.Mitra Telindo Nusantaramemberikan penilaian dalam pengangkatan calon supervisor agar Sumber Daya Manusia (SDM) yang terdapat diperusahaan dapat dioptimalkan sesuai dengan yang di harapkan perusahaan. Pengangkatan calon supervisor ini diberikan kepada setiap kepala toko cabang. Kepala toko cabang yang terpilih akan menempati jabatan supervisor area.

Berdasarkan hasil wawancara penulis dengan beberapa karyawan di PT. Mitra Telindo Nusantara, konsep penilaian kinerja karyawan dinilai kurang cocok jika digunakan untuk pengangkatan calon supervisor. Karena proses penilaian yang dilakukan secara manual dan dilihat dari kehadiran dan masa kerja saja sehingga penilaian tidak objektif.Penilaian karyawan di PT.Mitra Telindo Nusantara yang masih dilakukan secara manual membuat proses penilaian membutuhkan waktu yang lama dan tidak akurat, dikarenakan proses penilaian yang bersifat subyektif sehingga diperlukan analisis pendukung keputusan untuk menentukan calon supervisor.

Salah satu metode yang digunakan untuk mendukung keputusan adalah metode Fuzzy Analytical Hierarchy Process (FAHP). F-AHP merupakan suatu metode analisis yang dikembang dari AHP dengan pendekatan konsep Triangular Fuzzy Number (TFN). F-AHP dianggap lebih baik dalam mendeskripsikan keputusan yang samar-samar dari pada AHP.[2]

Berdasarkan penelitian terdahulu, terdapat pengambilan keputusandengan metode FAHP didapat nilai konsistensi ratio sebesar 0,04 yang bernilai lebih kecil dari 10\% yang berarti matriks yang digunakan bernilai konsisten. Bobot kriteria yang dihasilkan dari metode FAHP, yaitu Absensi 48\%, Masa Kerja 32\%, Jabatan $6 \%$, dan Kinerja 14\% untuk menentukan penilaian bonus akhir tahun karyawan.[3]Penelitian lainnya digunakan dalam penentuan mustahik (penerima zakat) dengan metode Fuzzy Analytical Hierarchy dari hasil perhitungan dari 60 data, didapat akurasi sebesar $91.67 \%$ dimana 5 data yang berbeda yang dihasilkan sistem dengan data dari pihak rumah zakat malang.[2]

Penelitian ini diharapkan dapat memberikan solusi dalam menentukan calon supervisor dan meningkatkan kualitas kerja karyawan dari hasil perhitungan dengan metode FAHP sesuai dengan kriteria yang ditentukan perusahaanserta membantu kinerja manajemen perusahaan.

Penelitian ini dilakukan untuk menghasilkan suatu sistem pendukung keputusan yang dapat membantu perusahaan dalam menentukan calon supervisor dan menerapkan metode FAHP yang bertujuan untuk meningkatkan ketepatan dan efektivitas penilaian terhadap calon supervisor sehingga proses pengangkatan karyawan dapat berjalan dengan baik karena sumber daya manusia yang terkelola dengan baik.

\section{Tinjauan PUSTaKa}

\section{A. Supervisor}

Supervisor adalah kepala disetiap bagian pekerjaan tertentu dan memiliki tanggung jawab yang cukup besar terhadap karyawan bawahannya untuk tercapainya tujuan perusahaan. Supervisor merupakan bagian penting dalam manajemen yang terlibat langsung dalam konteks pekerjaan individu, memberikan arahan, mengatur, mengawasi serta bertanggungjawab karena dukungan supervisor memiliki pengaruh langsung terhadap perilaku bawahan.[4] 


\section{B. Sistem Pendukung Keputusan}

Sistem pendukung keputusan adalah suatu sistem informasi berbasis komputer yang menghasilkan berbagai alternatif keputusan untuk membantu manajemen dalam menangani berbagai permasalahan yang terstruktur ataupun tidak terstruktur dengan menggunakan data atau model. Konsep pendukung keputusan ditandai dengan sistem interaktif berbasis komputer yang membantu pengambil keputusan memanfaatkan data dan model untuk menyelesaikan masalah-masalah yang tidak terstruktur.

Pada dasarnya SPK dirancang untuk mendukung seluruh tahap pengambilan keputusan mulai dari mengidentifikasi masalah, memilih data yang relevan, menentukan pendekatan yang digunakan dalam proses pengambilan keputusan, sampai mengevaluasi pemilihan alternative. Pengertian sistem pendukung keputusan yang dikemukakan oleh Michael S Scott Morton dan Peter G W Keen, dalam buku Sistem Informasi Manajemen (McLeod, 1998) menyatakan bahwa sistem pendukung keputusan merupakan sistem penghasil informasi yang ditujukan pada suatu masalah yang harus dibuat oleh manajer.[5]

\section{Fuzzy Analitycal Hierarchy Process (Fuzzy AHP)}

Fuzzy AHP merupakan salah satu metode yang dapat digunakan untuk mengetahui seberapa pentingnya Sistem Pendukung Keputusan dalam menentukan merk produk detergen terbaik. Fuzzy AHP ini dikembangkan oleh Chang pada tahun 1996 yang merupakan turunan dari metode AHP (Analytical Hierarchy Process) yang menjelaskan masalah multi faktor atau multi kriteria secara kompleks untuk menjadi suatu hirarki, sehingga permasalahan akan tampak lebih terstruktur dan sistematis. Metode Fuzzy AHP dapat dikatakan lebih baik karena mampu menutupi kelemahan yang terdapat pada metode AHP yaitu permasalahan terhadap kriteria yang memiliki sifat subjektif lebih banyak.

Penentuan derajat keanggotaan F-AHP yang dikembangkan oleh Chang (1996) menggunakan fungsi keanggotaan segitiga (Triangular Fuzzy Number/TFN). Fungsikeanggotaansegitiga merupakangabunganantaraduagaris(linear).[6]

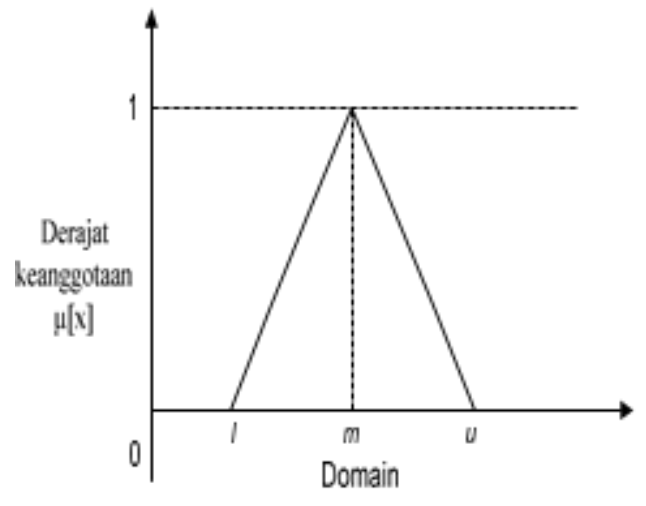

Gambar 1. Fungsi Keanggotaan Segitiga [6]

(Chang,1996) mendefinisikan nilai intensitas AHP ke dalam skala fuzzy segitiga yaitu membagi tiap himpunan fuzzy dengan dua (2), kecuali untuk intensitas kepentingan satu (1). Skala fuzzy segitiga yang digunakan Chang dapat dilihat pada Tabel berikut.

Tabel I. SkalaNilaiFuzzySegitiga[6]

\begin{tabular}{|c|l|c|}
\hline $\begin{array}{c}\text { Skala } \\
\text { AHP }\end{array}$ & \multicolumn{1}{|c|}{ Skala Fuzzy } & $\begin{array}{c}\text { Invers Skala } \\
\text { Fuzzy }\end{array}$ \\
\hline 1 & $\begin{array}{l}1=(1,1,1)=\text { jika } \\
\text { diagonal } \\
(1,1,3)= \\
\text { selainnya }\end{array}$ & $(1 / 3,1 / 1,1 / 1)$ \\
\hline 3 & $3=(1,3,5)$ & $(1 / 5,1 / 3,1 / 1)$ \\
\hline 5 & $5=(3,5,7)$ & $(1 / 7,1 / 5,1 / 3)$ \\
\hline 7 & $7=(5,7,9)$ & $(1 / 9,1 / 7,1 / 5)$ \\
\hline 9 & $9=(7,9,9)$ & $(1 / 9,1 / 9,1 / 7)$ \\
\hline 2 & $2=(1,2,4)$ & $(1 / 4,1 / 2,1 / 1)$ \\
4 & $4=(2,4,6)$ & $(1 / 6,1 / 4,1 / 2)$ \\
6 & $6=(4,6,8)$ & $(1 / 8,1 / 6,1 / 4)$ \\
8 & $8=(6,8,9)$ & $(1 / 9,1 / 8,1 / 6)$ \\
\hline
\end{tabular}




\section{Langkah F-AHP}

Langkah penyelesaian F-AHP adalah sebagai berikut[7]

a. Membuat struktur hirarki masalah yang akan diselesaikan dan menentukan perbandingan matriks berpasangan antar kriteria dengan skala TFN seperti pada Tabel 1.

b. Menentukan nilai sintesis fuzzy ( $\mathrm{Si}$ ) prioritas dengan rumus,

$S i=\sum_{j=1}^{m} M_{i}^{j} \times \frac{1}{\sum_{i=1}^{n} \sum_{j=1}^{m} M_{i}^{j}}$

Dimana

$\sum_{j=1}^{m} M_{i}^{j}=\sum_{j=1}^{m} l j, \sum_{j=1}^{m} m j, \sum_{j=1}^{m} u j$

Sedangkan

$\frac{1}{\sum_{j=1}^{n} \sum_{j=1}^{m} M_{i}^{j}}=\frac{1}{\sum_{i=1}^{n} u i, \sum_{i=1}^{n} m i, \sum_{i=1}^{n} l i}$

c. Menentukan nilai vektor (V) dan nilai Ordinat Defuzzifikasi (d') Jika hasil yang diperoleh pada setiap matrik fuzzy,

$M_{i} M_{2} \geq M_{1}\left(M_{2}=\left(l_{2}, m_{2}, u_{2}\right)\right.$ dan $M_{2}=\left(l_{1}, m_{1}, u_{1}\right)$ maka nilai vektor dapat dirumuskan sebagai berikut:

$V(M 2 \geq M 1)=\sup \left[\min \left(\mu M_{1}(x), \min \left(\mu M_{2}(y)\right)\right)\right]$ atau sama dengan grafik pada gambar berikut :

$V(M 2 \geq M 1)=f(x)= \begin{cases}1, & \text { if } m_{2} \geq m_{1} \\ & 0, \quad \text { if } l_{1} \geq \mu_{2}, \\ & \frac{l_{1}-\mu_{2}}{\left(m_{2}-\mu_{2}\right)-\left(m_{1}-l_{1}\right)}\end{cases}$

Jika hasil nilai fuzzy lebih besar dari $\mathrm{k}, \mathrm{M}_{\mathrm{i}}(\mathrm{i}=1,2, \mathrm{k})$ maka nilai vektor dapat di definisikan sebagai berikut:

$V\left(M \geq M_{1}, M_{2, \ldots \ldots .,} M_{k}\right)=V\left(M \geq M_{1}\right)$ dan

$V\left(M \geq M_{2}\right)$ dan $V\left(M \geq M_{K}\right)=\min V\left(M \geq M_{1}\right)$.

Asumsikan bahwa,

$d^{\prime}(A i)=\min V(S i \geq S k)$

Untuk $\mathrm{k}=1,2, \ldots, \mathrm{n} ; \mathrm{k} \neq \mathrm{I}$, maka diperoleh nilai bobot vector

$W^{\prime}=\left(d^{\prime}\left(A_{1}\right), d^{\prime}\left(A_{2}\right), \ldots, d^{\prime}\left(A_{n}\right)\right)^{\mathrm{T}}$

Dimana $A_{i}=1,2, . ., \mathrm{n}$ adalahn element keputusan

d. Normalisasi nilai bobot vektor fuzzy (W)

Setelah dilakukan normalisasi daripersamaan (7)maka nilai bobot vektor yang ternormalisasi adalah seperti rumus berikut:

$W=\left(d^{\prime}\left(A_{1}\right), d\left(A_{2}\right), \ldots, d^{\prime}\left(A_{n}\right)\right)^{\mathrm{T}}$

Dimana $\mathrm{W}$ adalah non fuzzy 


\section{METODE PENELITIAN}

\section{A. Kerangka Pemikiran}

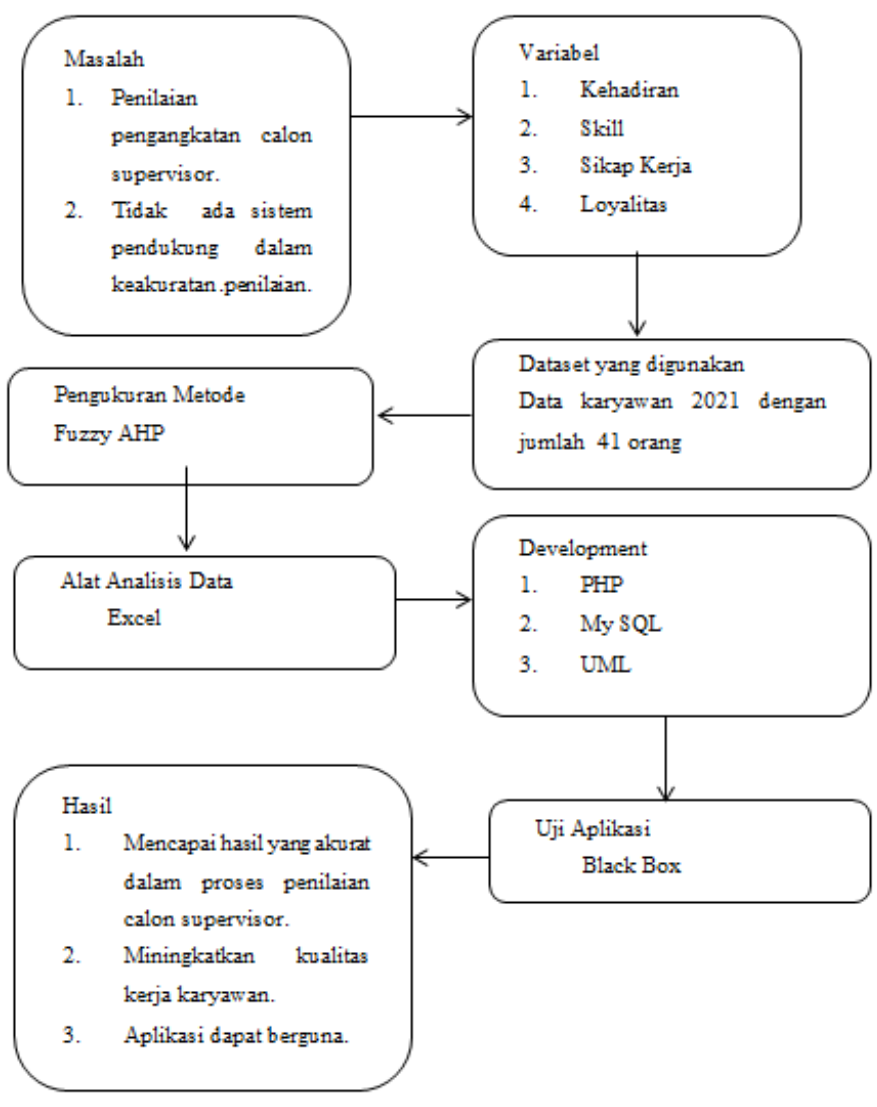

Gambar 2. Kerangka Pemikiran

\section{B. Metode Penelitian}

Metode yang digunakan dalam penelitian ini adalah metode penelitian deskriptif, yaitu memberikan gambaran tentang fenomena yang ada atau aspek lingkupan penilaian dari tempat yang diteliti. Metode deskriptif tidak hanya pengumpulan data, tetapi meliputi analisis tentang data.

\section{Metode Pengumpulan Data}

Metode pengumpulan data yang dilakukan peneliti yaitu dengan cara melakukan observasi, Peneliti datang langsung ke PT. Mitra Telindo Nusantara untuk mendapatkan data karyawan, melakukan wawancara kepada pihak-pihak terkait yang memahami mengenai kegiatan, melakukan studi pustaka dengan cara mengumpulkan dan mengidentifikasi serta mengolah data tertulis berbentuk buku-buku yang berkaitan dengan penelitian.

a. Observasi

Metode ini diterapkan dengan mendatangi obyek perusahaan, yaitu dengan melakukan secara langsung di tempat penelitian untuk mengetahui secara jelas dan terinci setiap permasalahan yang ada.

b. Wawancara

Pengumpulan data dilakukan melalui wawancara untuk mengumpulkan informasi dengan mengajukan sejumlah pertanyaan secara lisan. Dalam penelitian ini peneliti mengajukan pertanyaan kepada pihak-pihak terkait yaang paham mengenai kegiatan yang berkaitan dengan proses penilaian calon supervisor untuk mengetahui penentuan nilai kepentingan pada setiap kriteria. Dalam hal ini, penulis melakukan wawancara kepada bagian HRD.

c. Studi Pustaka

Pengumpulan data dengan cara melakukan studi pustaka melalui membaca buku-buku referensi, jurnal penelitian sejenis yang dapat mendukung penulisan skripsi ini, yang menjelaskan tentang Sistem Pendukung Keputusan dengan menggunakan metode FuzzyAnalytical Hierarcy Process (FAHP). Studi Pustaka digunakan untuk mengetahui solusi yang tepat untuk mengolah data sehingga dapat dituangkan kedalam metode yang digunakan didalam penelitian. 
JURSISTEKNI (Jurnal Sistem Informasi dan Teknologi Informasi) Vol 3, No.3, September 2021: Hal 32- 40

ISSN. P: 2715-1875, E: 2715-1883

\section{PEMbahasan}

\section{A. DataKriteria}

Setelahdilakukanwawancaradenganpihakmanajemen PT. Mitra Telindo Nusantaramaka diperoleh data kriteria yangdigunakandalampemilihancalon

SupervisorsepertiterlihatpadaTabel2.BerdasarkanTabel2terlihatbahwaterdapatLima (5)kriteria.

\begin{tabular}{|l|}
\multicolumn{1}{|c|}{ KabelII.Data Kriteria } \\
\hline Sikap \\
\hline Kehadiran \\
\hline Pengetahuan Kerja \\
\hline Penjualan \\
\hline Masa Kerja \\
\hline
\end{tabular}

\section{B. Langkah Penelitian dengan Metode F-AHP}

\section{StrukturHirarki}

Strukturhirarkidaripermasalahanpemilihancalon supervisordapatdilihatpadaGambar3.Sedangkan perbandingan matriks berpasangan antarkriteriadenganskalaTFNdapatdilihatpada Tabel 3.

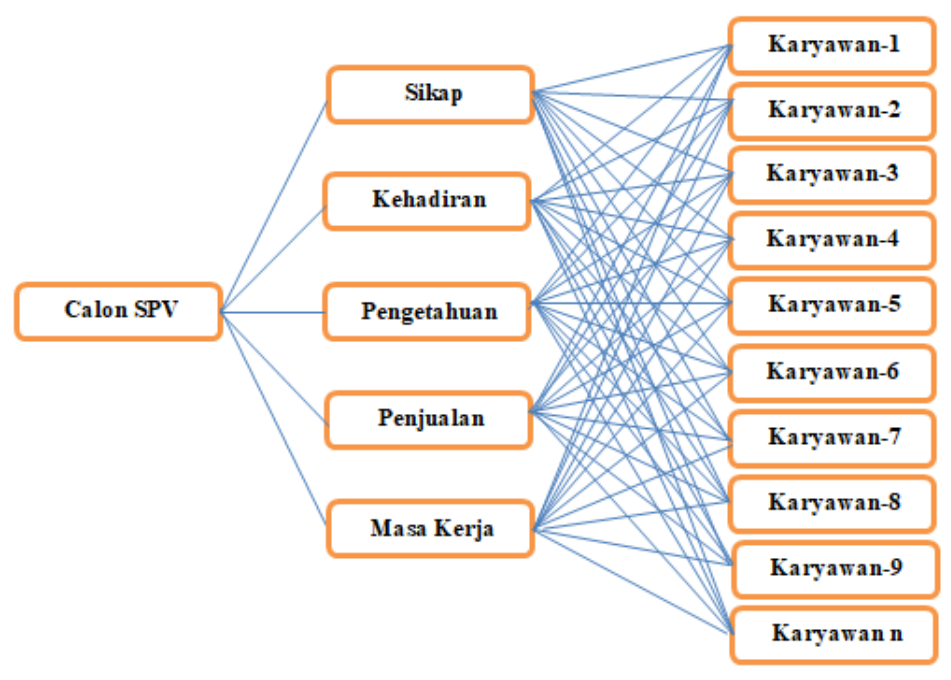

Gambar 3. Struktur Hirarki

\section{Menghitung Nilai Geometrik Mean}

Menentukan tingkat kepentingan dengan menghitung rata-rata geometrik pada setiap baris, yakni dengan mengambil akar $\mathrm{n}$ dari perkalian nilai-nilai pada sel yang terdapat pada baris matriks tersebut. $\mathrm{n}$ adalah banyaknya kriteria/alternatif. Hasil dari geometrik mean dapat diperlihatkan pada tabel 9 dibawah ini.

\begin{tabular}{|c|c|c|c|c|c|c|c|c|c|c|c|c|c|c|c|c|c|c|c|c|c|}
\hline \multirow{2}{*}{ Kriteria } & \multicolumn{3}{|c|}{ Sikap } & \multicolumn{3}{|c|}{ Kehadiran } & \multicolumn{3}{|c|}{ Pengetahuan } & \multicolumn{3}{|c|}{ Penjualan } & \multicolumn{3}{|c|}{ Masa Kerja } & \multicolumn{3}{|c|}{ Jumlah } & \multicolumn{3}{|c|}{ Geometrik Mean } \\
\hline & 1 & $\mathrm{~m}$ & $\mathrm{u}$ & 1 & $\mathrm{~m}$ & $\mathrm{u}$ & 1 & $\mathrm{~m}$ & $\mathrm{u}$ & 1 & $\mathrm{~m}$ & $\mathrm{u}$ & \begin{tabular}{l|l}
1 & 1 \\
\end{tabular} & $\mathrm{~m}$ & $\mathrm{u}$ & 1 & $\mathrm{~m}$ & $\mathrm{u}$ & 1 & $\mathrm{~m}$ & $\mathrm{u}$ \\
\hline Sikap & 1 & 1 & 1 & 1 & 1 & 1 & 3 & 5 & 7 & 3 & 5 & 7 & 7 & 9 & 9 & 63 & 225 & 441 & 2.290 & 2.954 & 3.380 \\
\hline Kehadiran & 1 & 1 & 1 & 1 & 1 & 1 & 1 & 3 & 5 & 3 & 5 & 7 & 5 & 7 & 9 & 15 & 105 & 315 & 1.719 & 2.537 & 3.160 \\
\hline Pengetahuan & 0.14 & 0.2 & 0.33 & 0.2 & 0.33 & 1 & 1 & 1 & 1 & 1 & 3 & 5 & 3 & 5 & 7 & 0.084 & 0.99 & 11.55 & 0.609 & 0.998 & 1.631 \\
\hline Penjualan & 0.14 & 0.2 & 0.33 & 0.14 & 0.2 & 0.33 & 0.2 & 0.33 & 1 & 1 & 1 & 1 & 3 & 5 & 7 & 0.012 & 0.066 & 0.762 & 0.411 & 0.581 & 0.947 \\
\hline Masa Kerja & 0.11 & 0.11 & 0.14 & 0.11 & 0.14 & 0.2 & 0.14 & 0.2 & 0.33 & 0.14 & 0.2 & 0.33 & 1 & 1 & 1 & 0.000 & 0.001 & 0.003 & 0.188 & 0.228 & 0.314 \\
\hline & & & & & & & & & & & & & & & & & & Jumlah & 5.218 & 7.297 & 9.432 \\
\hline
\end{tabular}

\section{Penjumlahan Tiap Sisi Geometrik Mean}


Pada tahap ini satu dibagi jumlah dari tiap kolom geometrik mean dan dikalikan dengan masing masing geometrik mean tiap sisi, baik itu sisi bawah, tengah dan atas. Hal ini dapat diperlihatkan pada tabel 10 dibawah ini.

Tabel X. . Proses penjumlahan tiap sisi geometrik mean

\begin{tabular}{|l|c|c|c|c|c|c|}
\hline \multirow{2}{*}{ Kriteria } & 1 & $\mathrm{~m}$ & $\mathrm{u}$ & \multicolumn{3}{c|}{ Jumlah } \\
\cline { 5 - 8 } & & & & 1 & $\mathrm{~m}$ & $\mathrm{u}$ \\
\hline Sikap & 2.290 & 2.954 & 3.380 & 0.192 & 0.137 & 0.106 \\
\hline Kehadiran & 1.719 & 2.537 & 3.160 & 0.192 & 0.137 & 0.106 \\
\hline Pengetahuan & 0.609 & 0.998 & 1.631 & 0.192 & 0.137 & 0.106 \\
\hline Penjualan & 0.411 & 0.581 & 0.947 & 0.192 & 0.137 & 0.106 \\
\hline Masa Kerja & 0.188 & 0.228 & 0.314 & 0.192 & 0.137 & 0.106 \\
\hline
\end{tabular}
ini.

Hasil dari perhitungan penjumlahan tiap sisi geometrik mean adalah seperti pada tabel 11 dibawah Tabel XI.Hasil perhitungan penjumlahan tiap sisi geometrik mean

\begin{tabular}{|l|l|l|l|}
\hline \multirow{2}{*}{ Kriteria } & \multicolumn{3}{|c|}{$\mathrm{Si}$} \\
\cline { 2 - 4 } & 1 & $\mathrm{~m}$ & $\mathrm{u}$ \\
\hline Sikap & 0.439 & 0.405 & 0.358 \\
\hline Kehadiran & 0.329 & 0.348 & 0.335 \\
\hline Pengetahuan & 0.117 & 0.137 & 0.173 \\
\hline Penjualan & 0.079 & 0.080 & 0.100 \\
\hline Masa Kerja & 0.036 & 0.031 & 0.033 \\
\hline
\end{tabular}

\section{Penentuan Nilai Vektor (V) Dan Nilai Ordinat Defuzzifikasi (d')}

Dalam tahap ini dilakukan proses untuk mencari nilai vektor untuk tiap sel dengan menggunakan persamaan 5 dan 6 . Pada persamaan tersebut jika nilai $\mathrm{m} 2>=\mathrm{m} 1$ maka nilai vektor bernilai 1 , tetapi jika sebaliknya maka nilai vektor menggunakan persamaan. Dan terakhir dicari nilai terendah dari nilai vektor tiap barisnya. Hasilnya dapat diperlihatkan pada tabel XII. dibawah ini.

\begin{tabular}{|l|r|r|r|r|r|r|}
\hline \multicolumn{1}{|c}{ Triteria } & Sikap & Kehadiran & Pengetahuan & Penjualan & Masa Kerja & \multicolumn{1}{c|}{ W } \\
\hline Sikap & & 2.23 & -126.16 & 25.59 & 12.66 & -126.16 \\
\hline Kehadiran & 1.00 & & -2.88 & -5.86 & -14.63 & -14.63 \\
\hline Pengetahuan & 1.00 & 1.00 & & -0.40 & -3.79 & -3.79 \\
\hline Penjualan & 1.00 & 1.00 & 1.00 & & -16.26 & -16.26 \\
\hline Masa Kerja & 1.00 & 1.00 & 1.00 & 1.00 & & 1.00 \\
\hline \multicolumn{7}{|c|}{ Jumlah } \\
\hline
\end{tabular}

\section{Normalisasi}

Setelah memperoleh nilai defuzzifikasi, maka langkah terakhir ialah dengan melakukan normalisasi dengan cara membagi nilai terkecil dari defuzzifikasi (W) dengan total dari defuzzifikasi dalam kolom. Adapun hasilnya dapat diperlihatkan pada tabel 13 dibawah ini.

Tabel XIII. Normalisasi

\begin{tabular}{|l|r|}
\hline \multicolumn{2}{|c|}{ Normalisasi } \\
\hline Sikap & 0.789 \\
\hline Kehadiran & 0.092 \\
\hline Pengetahuan & 0.024 \\
\hline Penjualan & 0.102 \\
\hline Masa Kerja & -0.006 \\
\hline
\end{tabular}

\section{Perankingan Alternatif dan Hasil Keputusan}


DariprosespenghitunganF-AHPkriteriadiperoleh bobot lokal ( $\left.W_{\text {lokal }}\right)$ yang akandikalikandengannilaialternatif. Tabel 14 berikut ini merupakantabelkesimpulanperangkingan alternatif 10 terbesar.

Tabel XIV. Kesimpulan dan Perangkingan alternatif

\begin{tabular}{|l|r|r|}
\hline \multicolumn{1}{|c|}{ Nama } & Rata-rata & Rangking \\
\hline Cut Nurbaeti & 0.997 & 1 \\
\hline Rahmi & 0.976 & 2 \\
\hline Deni & 0.940 & 3 \\
\hline Arbagin Bakri & 0.936 & 4 \\
\hline Hanafi & 0.931 & 5 \\
\hline Fajar Maulana & 0.837 & 6 \\
\hline Iman & 0.825 & 7 \\
\hline Tarmidi & 0.824 & 8 \\
\hline Rony Saputera & 0.824 & 8 \\
\hline Fitri & 0.823 & 10 \\
\hline
\end{tabular}

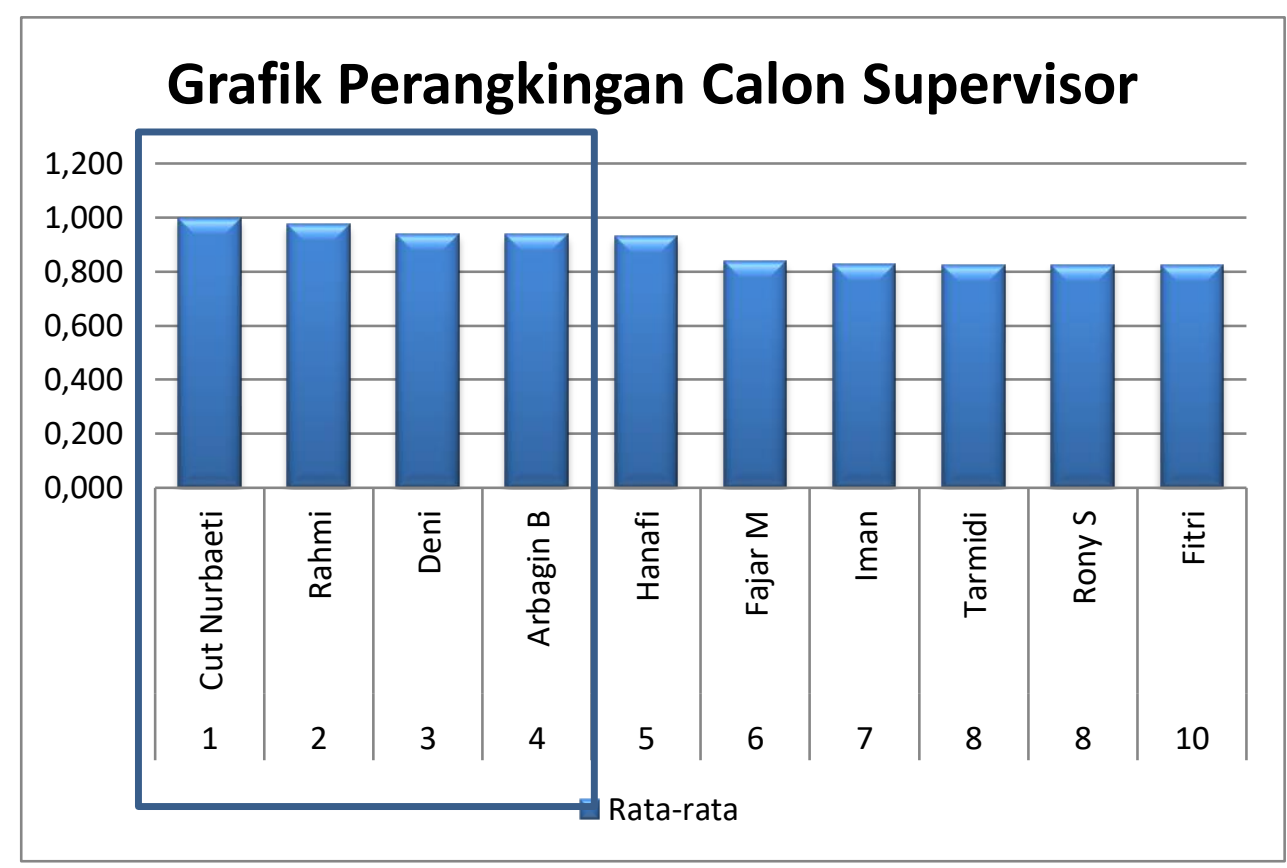

Gambar . Grafik Calon SPV

\section{KESIMPULANDAN SARAN}

Berdasarkan analisa yang telah dilakukan oleh peneliti, dapat disimpulkan bahwa terdapat 4(empat) rekomendasi calon spv terbaikyaitu Cut Nurbaeti dengan bobot 0.997, Rahmi dengan bobot 0.976, Deni 0.940, dan Arbagin Bakri 0.936. Sistem pendukung keputusan pemilihan supervisor ini dapat mempermudah bagian HRD dalam menentukan keputusan untuk memilih supervisor. Sistem pendukung keputusan ini efektif dan efisien dalam penggunaan waktu, maupun tenaga bagi user yang menggunakannya. Sistem Pendukung Keputusan dengan metode Fuzzy AHP ini dapat diterapkan pada penilaian calon supervisor.

\section{DAFTAR Pustaka}

[1] A. F. F. Madjri and B. Santoso, "Pengukuran Kinerja Sumber Daya Manusia Dengan Menggunakan Metode Human Resources Scorecard Di Pt. Xyz,” Juminten, vol. 2, no. 2, pp. 1-12, 2021, doi: 10.33005/juminten.v2i2.227.

[2] R. A. Iswara, E. Santoso, and B. Rahayudi, "Sistem Pendukung Keputusan Untuk Penentuan Mustahik (Penerima Zakat) Menggunakan Metode Fuzzy AHP (F-AHP),” J. Pengemb. Teknol. Inf. 
dan Ilmu Komput. Univ. Brawijaya, vol. 2, no. 3, pp. 1306-1312, 2018.

[3] P. P. Putra, I. G. A. Gunadi, I. M. Windu, and A. Kesiman, "Jurnal Ilmu Komputer Indonesia ( JIK ), Volume 6, No: 1, Februari 2021 Model Analisis Penentuan Bonus Akhir Tahun Karyawan Berdasarkan Metode Fuzzy AHP ( Studi Kasus : PT . Baliyoni Saguna ) Jurnal Ilmu Komputer Indonesia ( JIK ), Volume 6, No : 1 ," vol. 6, no. M, pp. 9-16, 2021.

[4] M. Mesran, N. Huda, S. N. Hutagalung, K. Khasanah, and A. Iskandar, "Sistem Pendukung Keputusan Pemilihan Supervisor Terbaik Pada Bagian Perencanaan Pt. Pln (Persero) Area Medan Menerapkan Preference Selection Index," KOMIK (Konferensi Nas. Teknol. Inf. dan Komputer), vol. 2, no. 1, 2018.

[5] D. Gustian, A. Bahrum, and S. Saepudin, "Sistem keputusan penilaian kinerja karyawan dengan menggunakan metode analitical hierracy process," J. TAM (Technology Accept. Model., vol. 9, no. 2, pp. 93-95, 2018.

[6] M. Fajri, R. R. M. Putri, and L. Muflikhah, "Implementasi Metode Fuzzy Analytic Hierarchy Process (F-AHP) dalam Penentuan Peminatan di MAN 2 Kota Serang," J. Pengemb. Teknol. Inf. dan Ilmu Komput., vol. 2, no. 5, pp. 2109-2117, 2018.

[7] W. Setiyaningsih and A. Y. E. Prasetyo, "Penerapan Fuzzy Ahp Untuk Peningkatan Ketepatan Dan Efektivitas Penilaian Kinerja Karyawan,” Kurawal - J. Teknol. Inf. dan Ind., vol. 1, no. 1, pp. 2133, 2018, doi: 10.33479/kurawal.2018.1.1.21-33.

[8] A. K. Sianipar, B. Sulistyo, and L. Widyastuti, "Perancangan Peformance Appraisal Menggunakan Metode Integrasi Rating Scale Dan Fuzzy Ahp (studi Kasus Cv Intech)," eProceedings Eng., vol. 6, no. 2, 2019.

[9] E. Yilmaz İnce and M. İnce, “Automatic e-content sequencing system for personalised learning environments by using fuzzy AHP based on multiple intelligences," J. Inf. Sci., p. $01655515211041333,2021$.

[10] M. Weigthing, P. Wp, F. Ilmu, and U. Sains, "Sistem pendukung keputusan penerimaan supervisor pada pt mitra suara sejati dengan metode weigthing product (wp) *)," vol. 4, no. 1, pp. 1-10, 2016.

[11] Z. Navita, "Sistem Pendukung Keputusan Pemilihan Supervisor Terbaik Dengan Menerapkan Metode Electre Pada Pt. Matahari Departement Store," vol. 7, no. April, pp. 457-465, 2019. 